\title{
The Performance of Ramsey Test, White Test and Terasvirta Test in Detecting Nonlinearity
}

\author{
Hendri Prabowo ${ }^{1}$, Suhartono ${ }^{2}$, Dedy Dwi Prastyo ${ }^{3}$ \\ Departement of Statistics, Faculty of Science and Data Analysis \\ Institut Teknologi Sepuluh Nopember (ITS) \\ J1. Arief Rahman Hakim, Surabaya 60111 Indonesia \\ Email: ${ }^{1}$ hendriprabowo88@gmail.com, ${ }^{2}$ suhartono@statistika.its.ac.id, ${ }^{3}$ dedy-dp@statistika.its.ac.id
}

\begin{abstract}
Abstrak- The objective of this research is to compare Ramsey test, White test and Terasvirta test in the identification of nonlinearity. Ramsey test is a test based on the regression specification error test. While White test and Terasvirta test are based on neural network models. The difference between White test and Terasvirta test is in determining its weight, White test based on random sampling, while Terasvirta test based on Taylor expansion. Simulation studies are carried out with various scenarios in each test by generating linear models, linear models with outliers and nonlinear models. The results of the simulation study showed that Terasvirta test had better power than Ramsey test and White test in detecting nonlinearity. Terasvirta test is also more sensitive to the presence of outliers in linear models.
\end{abstract}

Keywords: Nonlinearity, Power, Ramsey, Terasvirta, White.

\section{INTRODUCTION}

Recently, models in statistics became more complex. The model used is not only linear model but also nonlinear model [1]. Nonlinearity in data is caused by several things, i.e. the nonlinear relationship between variables and the existence of outliers. The outlier can change the pattern of data [2] as a model initially a linear model then becomes an outlier, so that changes this model to a nonlinear model. Problems that often occur in determining a linear or nonlinear model are effective ways to do a nonlinear detection. Often a model is considered linear but in reality is a nonlinear model. So it is necessary to determine an effective test in determining nonlinearity.

Nonlinearity tests have been extensively developed such as Ramsey test [3], White test [4] and Terasvirta test [5]. Ramsey test is the most common and easy to use in detecting nonlinearity. While White test and Terasvirta test are tests that use a neural network model. From the three tests need to determine which test is the best in identifying nonlinearity.

There were many studies that use nonlinearity test in their research. Wang et al. [6] used Terasvirta test in the identification of nonlinearity in his research. Lacheheb et al. [7] used Ramsey test for identification of nonlinearity. In general, from the previous research there is rarely any research comparing the power of the nonlinearity test. Previous research comparing several nonlinearity tests is Ahn et al. [8] compared eight nonlinearity tests i.e. Bispectrum, Hinich's Bicorrelation, BDS, Engle, Keenan, Tsay, Mcleod-Li and Ramsey. It was found that Ramsey, Keenan and Tsay had stronger power than the others. Lee et al. [9] compared Bonferoni, Keenan, Tsay, Mcleod-Li,
Bispectrum, BDS and White. Overall White test is better than other test.

In this research, several nonlinearity tests will be used i.e. Ramsey test, White test and Terasvirta test. Then the power test of each method will be compared, so the best test and the most sensitive test to identify nonlinearity is obtained. The rest of paper is organized as follows: Section 2 reviews the nonlinearity test i.e. Ramsey test, White test and Terasvirta test; Section 3 presents the design of study simulation; Section 4 presents the result of analysis and discussion; and Section 5 presents the conclusion of this study.

\section{NONLINEARITY TEST}

\section{A. Ramsey Test}

Ramsey proposed a method called RESET (regression specification error test) [10]. Suppose there are 2 variables, the predictor variable $(\mathrm{X})$ and the response variable $(\mathrm{Y})$. So we get a linear regression model:

$$
Y_{i}=\lambda_{1}+\lambda_{2} X_{i}+u_{i}
$$

If regression was applied, it will produce $\hat{Y}_{i}$ and $\hat{u}_{i}$. If $\hat{Y}_{i}$ and $\hat{u}_{i}$ plotted and seen there are still have patterns, then it is suspected that the model is not suitable. This means that it can still be modeled using $\hat{Y}_{i}$. The following are the steps of Ramsey test:

1. From model (1) gets $\hat{Y}_{i}$.

2. $\quad$ From model (1), if $\hat{Y}_{i}$ and $\hat{u}_{i}$ still have a pattern (can be based on a plot). Then, it is suspected that by adding $\hat{Y}_{i}$ in other forms such as $\hat{Y}_{i}^{2}$ and $\hat{Y}_{i}^{3}$ can increase the value of $\mathrm{R}^{2}$. So that the model is formed as follows:

$$
Y_{i}=\beta_{1}+\beta_{2} X_{i}+\beta_{3} \hat{Y}_{i}^{2}+\beta_{4} \hat{Y}_{i}^{3}+u_{i}
$$

3. After that, we calculated the value of $\mathrm{R}^{2}$ from model (1) and model (2). Then the F test is used as follows:

$$
F_{h i t}=\frac{\left(R_{\text {model2 }}^{2}-R_{\text {model1 }}^{2}\right) / k}{\left(1-R_{\text {model2 }}^{2}\right) /\left(n-p_{2}\right)}
$$

where $k$ is the number of additional predictors, $n$ is the number of observations and $p_{2}$ is the number of predictors in model (2).

4. If $F_{h i t}>F\left(\alpha, k, n-p_{2}\right)$ then reject $H_{0}$. The hypothesis is as follows:

$\mathrm{H}_{0}$ : Model 1 is suitable (Linear).

$\mathrm{H}_{1}$ : Model 1 is not suitable (Nonlinear).

Ramsey test is easy to use, it is one of advantages using Ramsey test. While the weakness is that it cannot determine the best alternative model. 


$$
F_{\text {hit }}=\frac{\left(S S R_{0}-S S R_{1}\right) / m}{S S R_{1} /(n-p-m-1)}
$$

\section{B. White Test}

White test is based on a neural network model [4]. In general, to see the relationship between two variables such as $\mathrm{X}$ and $\mathrm{Y}$, regression can be used. For example the equation of the neural network model is as follows (the following model consists of 1 hidden layer and q neurons):

$$
f(x, \theta)=\tilde{x} \gamma_{0}+\sum_{j=1}^{q} \beta_{j} \varphi\left(\tilde{x} \gamma_{j}\right)+u_{t}
$$

$$
\text { where } \tilde{x} \gamma_{0} \text { is linear component, } \sum_{j=1}^{q} \beta_{j} \varphi\left(\tilde{x} \gamma_{j}\right)
$$

nonlinear component, $\beta_{j}$ is the weight of the neural network model from the hidden layer to the output layer, $\gamma_{j}$ is the weight of the neural network model from the input layer to the hidden layer and $\varphi$ is a sigmoid activation function. When the value of $q=0$, there are only 2 layers, namely the input layer and the output layer only. And the model is linear. The null hypothesis in the White test is as follows:

$\mathrm{H}_{0}: \beta_{1}=\ldots=\beta_{q}=0$

or can be written :

$\mathrm{H}_{0}: \gamma_{1}=\ldots=\gamma_{q}=0$

The problem is how to determine $\gamma_{1}, \ldots, \gamma_{q}$. If the values of $\gamma_{1}, \ldots, \gamma_{q}$ has been determined, the value of $\varphi\left(\tilde{x} \gamma_{j}\right)$ can be calculated. Determination value of $\gamma_{1}, \ldots, \gamma_{q}$ based on randomly generated vectors from a possible distribution. Where $\gamma_{1}, \ldots, \gamma_{q}$ are mutually independent vectors. These components will be combined later with linear equations to be tested with White test.

White test can be tested using the chi-square distribution and $\mathrm{F}$ distribution. The procedure in White test with chi-square distribution is as follows:

1. Regress $Y_{i}$ with $1, X_{1}, \ldots, X_{p}$ and calculate the residual value $\hat{u}_{i}=Y_{i}-\hat{Y}_{i}$.

2. Regress $\hat{u}_{i}$ with $1, X_{1}, \ldots, X_{p}$ and $\mathrm{m}$ additional predictor, then calculate the coefficient of determination from regression $\left(\mathrm{R}^{2}\right)$. m predictors are values of $\varphi\left(\tilde{x} \gamma_{j}\right)$ which obtained from mutually independent random vectors.

3. Calculate $\mathrm{X}^{2}=n R^{2}$, where $\mathrm{n}$ is the number of observations. If $\mathrm{nR}^{2}>\mathrm{X}_{(\mathrm{m})}^{2}$, then reject $\mathrm{H}_{0}$.

Whereas the testing procedure with the $\mathrm{F}$ distribution is as follows:

1. Regress $Y_{i}$ with $1, X_{1}, \ldots, X_{p}$ and calculate the residual value $\hat{u}_{i}=Y_{i}-\hat{Y}_{i}$, and also calculate the value of $S S R_{0}=\sum \hat{u}_{i}^{2}$.

2. Regress $\hat{u}_{i}$ with $1, X_{1}, \ldots, X_{p}$ and $\mathrm{m}$ additional predictor. Then, calculate the residual value $\hat{v}_{i}=\hat{u}_{i}-\hat{u}_{i}$ and also calculate the value of $S S R_{1}=\sum \hat{v}_{i}^{2}$. m predictors are values of $\varphi\left(\tilde{x} \gamma_{j}\right)$ which obtained from mutually independent random vectors.

3. Calculate where $m$ is the number of additional predictors, $\mathrm{n}$ is the number of observations and $p$ is the number of initial model predictors. If $F_{\text {hit }}>F(\alpha, m, n-p-m-1)$ then reject $\mathrm{H}_{0}$.

\section{Terasvirta Test}

Terasvirta test is one of the nonlinear tests. This test is almost same as white test that is both using a neural network model. The difference is that in terravirta test the parameter values of the neural network model are based on taylor expansion [5] while the white test is randomly selected. Here is an example of a nonlinear model:

$$
y_{t}=\varphi\left(\gamma^{\prime} w_{t}\right)+\beta^{\prime} w_{t}+u_{t}
$$

where $\beta^{\prime} w$ is linear component, $\varphi\left(\gamma^{\prime} w_{t}\right)$ is nonlinear component, $\gamma^{\prime}$ is the weight of the neural network model from the input layer to the hidden layer for nonliner components, $\beta^{\prime}$ is the weight of the neural network model from the input layer to the output layer for linear components and $\varphi$ is a sigmoid activation function. This equation (6) can be written as:

$$
y_{t}=\beta^{\prime} w_{t}+\sum_{j=1}^{q} \theta_{0 j}\left\{\varphi\left(\gamma^{\prime} w_{t}\right)-\frac{1}{2}\right\}+u_{t}
$$

where $\theta_{0 j}$ is the weight of the neural network model from the hidden layer to the output layer for nonlinear components. If the nonlinear component is 0 then the data has a linear relationship. So the hypothesis is as follow:

$\mathrm{H}_{0}: \theta_{01}=\ldots=\theta_{0 q}=0$

or can be written :

$\mathrm{H}_{0}: \gamma_{1}=\ldots=\gamma_{q}=0$

The value of neural network parameters in the Teravista test uses taylor expansion so that a new model is obtained:

$$
\begin{aligned}
y_{t}= & \beta^{\prime} w_{t}+\sum_{i=1}^{p} \sum_{j=1}^{p} \delta_{i j} y_{t-i} y_{t-j} \\
& +\sum_{i=1}^{p} \sum_{j=1}^{p} \sum_{k=1}^{p} \delta_{i j} y_{t-i} y_{t-j} y_{t-k}+u_{t}
\end{aligned}
$$

If the quadratic and cubic component terms are 0 then fail to reject $\mathrm{H}_{0}$, so we get a linear model. Terasvirta test can be tested using the chi-square distribution and $\mathrm{F}$ distribution, it similar with White test. The procedure in Terasvirta test with chi-square distribution is as follows:

1. Regress $Y_{i}$ with $1, X_{1}, \ldots, X_{p}$ and calculate the residual value $\hat{u}_{i}=Y_{i}-\hat{Y}_{i}$.

2. Regress $\hat{u}_{i}$ with $1, X_{1}, \ldots, X_{p}$ and $\mathrm{m}$ additional predictor, then calculate the coefficient of determination from regression $\left(\mathrm{R}^{2}\right)$. $\mathrm{m}$ predictor is the quadratic and cubic component values of taylor expansion.

3. Calculate $\mathrm{X}^{2}=n R^{2}$, where $\mathrm{n}$ is the number of observations. If $\mathrm{nR}^{2}>\mathrm{X}_{(\mathrm{m})}^{2}$, then reject $\mathrm{H}_{0}$. 
Whereas the testing procedure with the $\mathrm{F}$ distribution is as follows:

1. Regress $Y_{i}$ with $1, X_{1}, \ldots, X_{p}$ and calculate the residual value $\hat{u}_{i}=Y_{i}-\hat{Y}_{i}$ and also calculate the value of $\operatorname{SSR}_{0}=\sum \hat{u}_{i}^{2}$.

2. Regress $\hat{u}_{i}$ with $1, X_{1}, \ldots, X_{p}$ and m additional predictor. Then, calculate the residual value $\hat{v}_{i}=\hat{u}_{i}-\hat{\hat{u}}_{i}$ and also calculate the value of $S S R_{1}=\sum \hat{v}_{i}^{2}$. $\mathrm{m}$ predictor is the quadratic and cubic component values of taylor expansion.

3. Calculate

$$
F_{h i t}=\frac{\left(S S R_{0}-S S R_{1}\right) / m}{S S R_{1} /(n-p-m-1)}
$$

where $\mathrm{m}$ is the number of additional predictors, $\mathrm{n}$ is the number of observations and $p$ is the number of initial model predictors. If $F_{\text {hit }}>\mathrm{F}(\alpha, \mathrm{m}, \mathrm{n}-\mathrm{p}-\mathrm{m}-1)$ then reject $\mathrm{H}_{0}$.

\section{METHODOLOGY}

In this research a simulation study will be conducted. Simulation studies are conducted to compare the power between Ramsey test, White test and Terasvirta test in detecting nonlinearity in linear models, linear models with outliers and nonlinear models. 1 linear model and 3 nonlinear models are used in the simulation performed. And the linear model used added 1, 3 and 5 outliers to detect sensitivity of each test in nonlinearity. The following are the models used:

a. Linear Model

Model $1 \rightarrow y_{1}=2 x_{1}+3 x_{2}+e$, where $\mathrm{e} \sim \mathrm{N}(0,0.2)$

b. Nonlinear Model

Model $2 \rightarrow y_{2}=2 x_{1}{ }^{2}+3 x_{2}{ }^{3}+e$, where $\mathrm{e} \sim \mathrm{N}(0,0.2)$

Model $3 \rightarrow y_{3}=e^{2 x_{1}+3 x_{2}}+e$, where $\mathrm{e} \sim \mathrm{N}(0,0.2)$

Model $4 \rightarrow y=e^{2 x_{1}{ }^{2}+0.5 x_{2}{ }^{2}}+e$, where $\mathrm{e} \sim \mathrm{N}(0,0.2)$

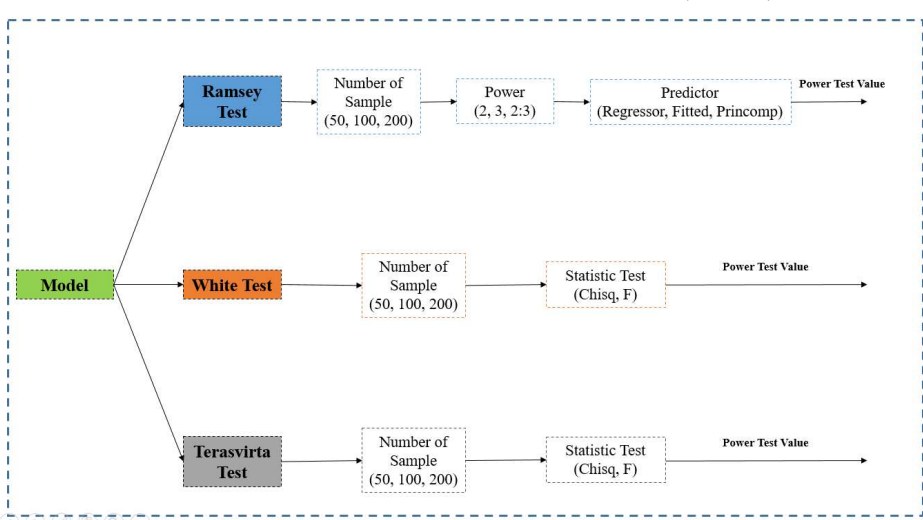

Figure 1. Simulation study scheme

The sample sizes used are 50,100 and 200. Simulation studies conducted using several different scenarios and sample sizes. For each scenario in each test 10000 replications will be carried out. Figure 1 is showed the scenarios for study simulation. The following is a complete explanation of the scenario for each nonlinearity test: a. Ramsey test, the Ramsey test will be tested on 3 types of power, i.e. 2 (quadratic), 3 (cubic) and 2: 3 (quadratic and cubic), and used 3 types of predictors i.e. regressor, fitted and princomp. So for each model will produce a total of 27 scenarios.

b. White test and Terasvirta test, in these two tests will be tried 2 different types of test statistics, i.e. F and Chisquare test. So for each model will produce a total of 6 scenarios.

\section{RESULT AND DISCUSSION}

\section{A. Data on Simulation Study Results}

Figure 2 and Figure 3 below show an illustration of the result simulation study from data. Each response variable in each model is plotted with each predictor variable. Based on Figure 1 it can be seen that for model 1, the response variable $\left(\mathrm{y}_{1}\right)$ has a fairly strong linear relationship with $\mathrm{x}_{2}$. Although there is no pattern of linear relationship with $\mathrm{x}_{1}$, but it can be said that model 1 is a linear model. In model 2, model 3 and model 4 it can be seen that the pattern of the relationship between each response variable and its predictors $\left(\mathrm{x}_{1}\right.$ and $\left.\mathrm{x}_{2}\right)$ does not indicate a linear relationship. So model 2, model 3 and model 4 are nonlinear models.

Based on Figure 3, it can be seen that for the initial model (model 1) is a model that has a pattern of linear relationships between response variables and predictors. Then 1 outlier, 3 outlier and 5 outlier was added. Visually it appears that the data pattern is still linear, but it will be proven whether the existence of outliers changes linearity. This will be discussed in section 4.2.2.
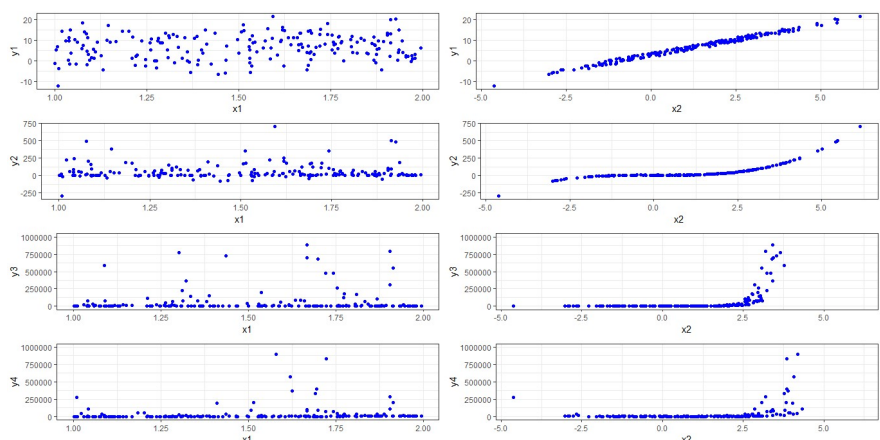

Figure 2. Data from simulation study 1

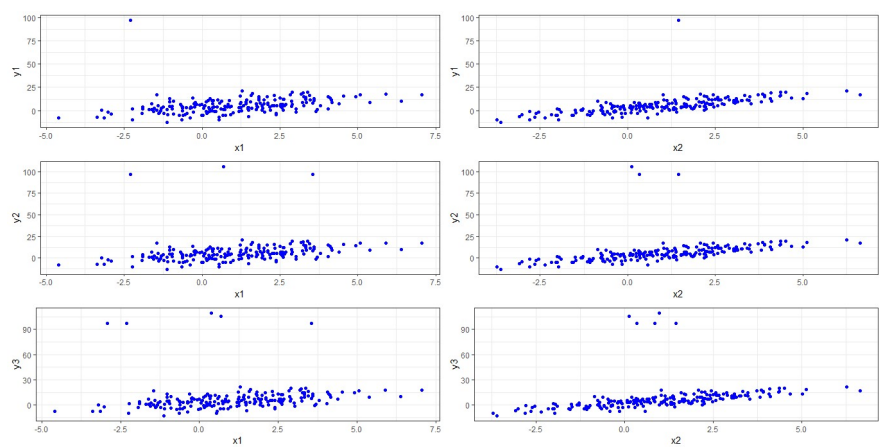

Figure 3. Data from simulation study 2

\section{B. Power Comparison for Each Nonlinearity Test}

Simulation studies conducted on each model in each scenario replicated 10000 times. Three sample sizes are used: 50 to represent small samples, 100 to represent medium samples and 200 to represent large samples. After 
testing, power will be calculated for each test. This power is the number of conclusions reject $\mathrm{H}_{0}$ (the model is a nonlinear model) in 10000 times test in each model in each scenario. Determination of the value of this power is based on values with a significance level of 0.05 .

\section{Power Comparison Result for Each Nonlinearity Test in Linear Model and Nonlinear Model}

From Figure 4 it can be seen that in general model 1 which is a linear model has power which approaches the level of significance 0.05 . Model 2, model 3 and model 4 which are nonlinear models, the power value is close to 1 . This does not only occur in the Ramsey test but also occurs in White test and Terasvirta test, it can be seen in Figure 5 and Figure 6.

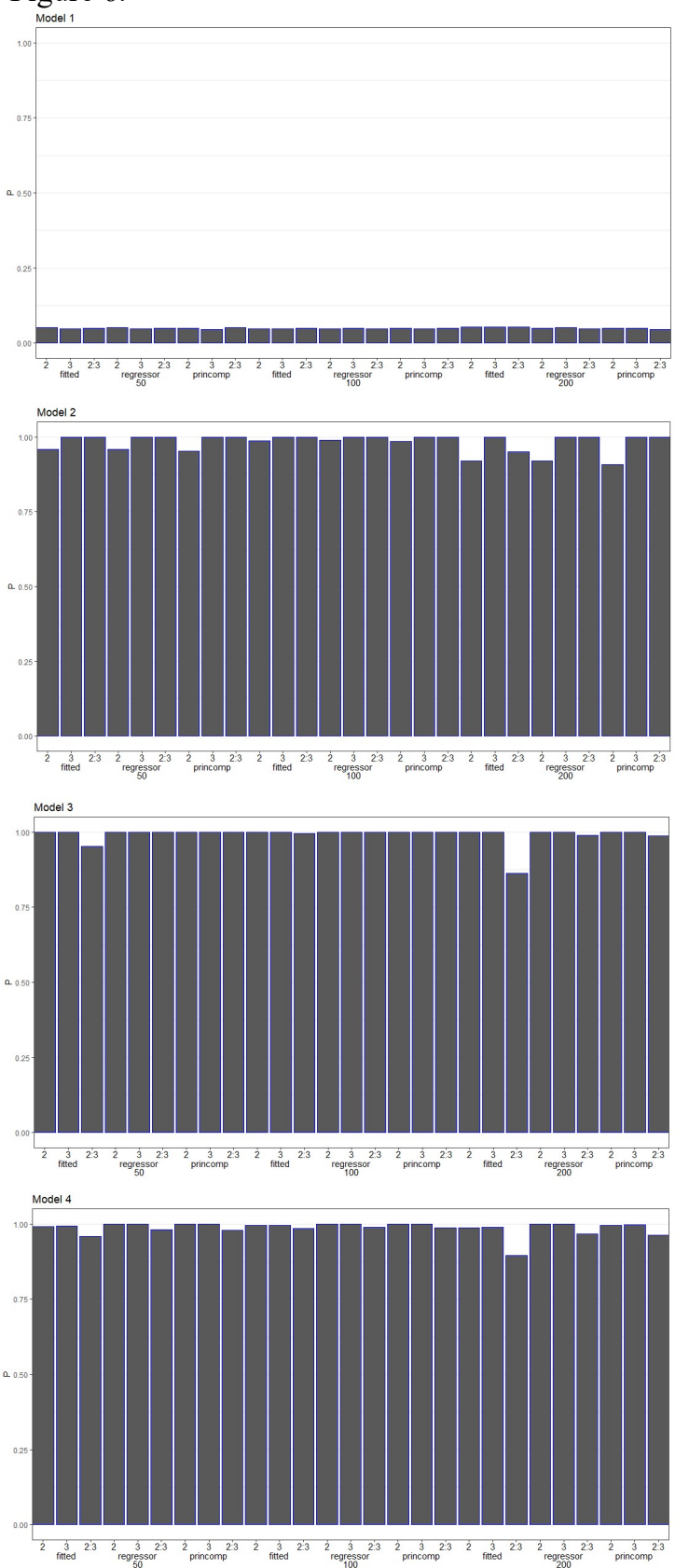

Figure 4. Ramsey's power test for linear and nonlinear models

In general, if the number of samples is used 100 power tests will tend to be very high. If the type of predictor used in the form of fitted power the test will generally be lower. Power is very dependent on the type of data used. For model 2 with power 2 the test power is low while for models 3 and 4 with power 2: 3 the test power is low.

Based on Figure 5 in general if the number of samples used as much as 100 power tests will tend to be very high. Whereas if the Chisq test is used it has a higher power test than if it uses the F test. Based on Figure 6, Terasvirta test power is not significantly influenced by the number of samples and statistics test. It can be seen in model 2, model 3 and model 4 the power is close to 1 for all scenarios. But from model 1 which is a linear model, using Chisq made the power of test will be higher.
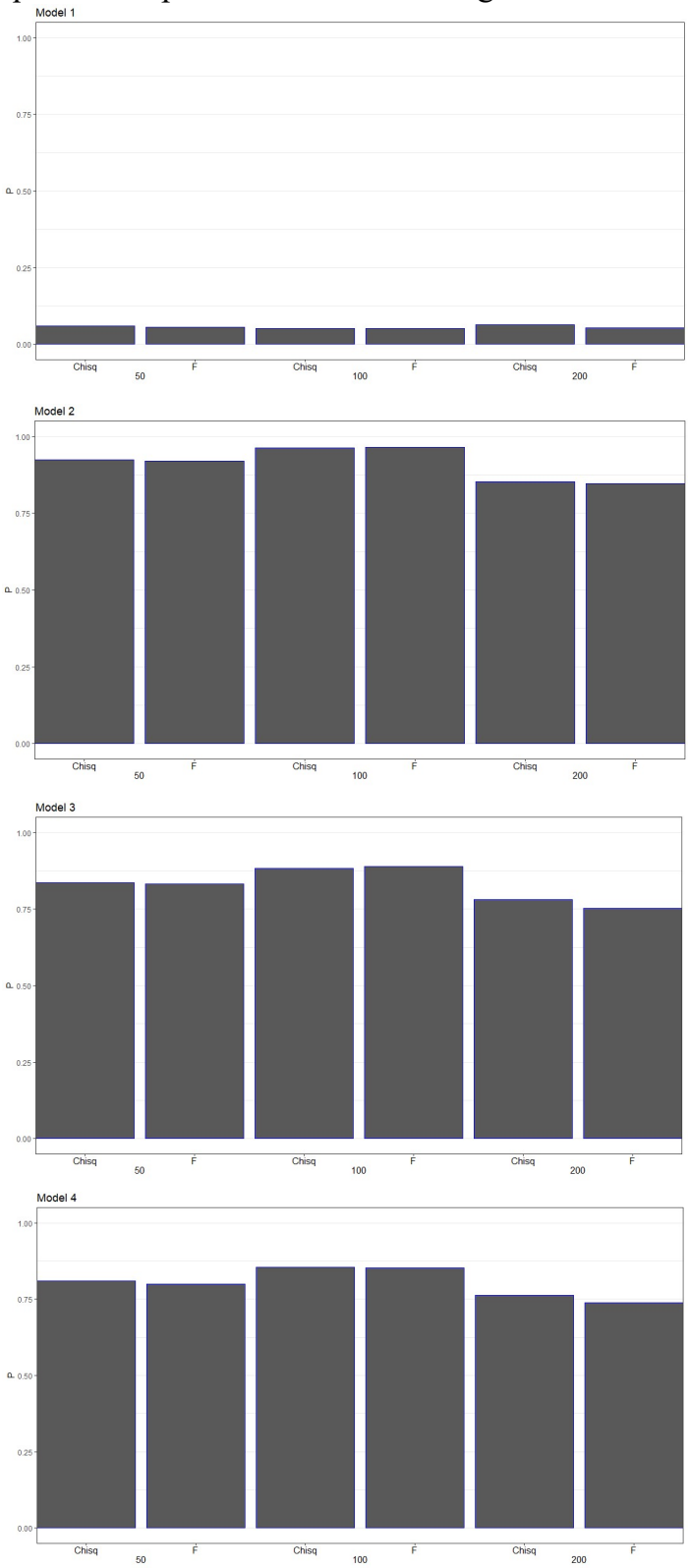

Figure 5. White's power test for linear and nonlinear models

From Table 1 and Table 2 it can be seen that for Ramsey test and Terasvirta test in the nonlinear model, the value of power test is close to 1 . But for White test, the value of power test is smaller than Ramsey test and White test. From Figure 4, Figure 5 and Figure 6 in detecting nonlinearity, Terasvirta test is the test that has the most powerful compared to Ramsey test and White test. For seeing the p-value consistency of each test at 10000 replications, it can use time series plots. 
From Figure 7 it can be seen that for model 1 using Ramsey test the results are consistent above 0.05 , it meaning that the resulting model is a linear model. These results are almost the same for White test and Ramsey test, it can be seen in Figure 7 and Figure 8. In model 2, model 3 and model 4 using several scenarios there are some homogeneous p-values and some heterogeneous p-values. But for the heterogeneity scenario is no bigger than White test. Based on Figure 8, it is known that for the nonlinear model, model 2, model 3 and model 4, the p-value is not homogeneous. These results are quite different when compared to Ramsey test and Terasvirta test.

From Figure 9 it is known that for model 1 using the Terasvirta test, it is almost same as Ramsey test and White test, it happen because it is a linear model. For the nonlinear model, model 2, model 3 and model 4 , the p-value from Terasvirta test is very homogeneous. The value is consistently below 0.05 . This means that Terasvirta test is quite good in nonlinearity test.

Table 1. Power value of Ramsey test on linear and nonlinear models

\begin{tabular}{|c|c|c|c|c|c|c|}
\hline $\begin{array}{c}\text { Sample } \\
\text { Size }\end{array}$ & $\begin{array}{c}\text { Type of } \\
\text { Predictor }\end{array}$ & $\begin{array}{l}\text { Type of } \\
\text { Power }\end{array}$ & $\begin{array}{c}\text { Model } \\
1 \\
\end{array}$ & $\begin{array}{c}\text { Model } \\
2 \\
\end{array}$ & $\begin{array}{c}\text { Model } \\
\mathbf{3} \\
\end{array}$ & $\begin{array}{c}\text { Model } \\
4 \\
\end{array}$ \\
\hline \multirow{9}{*}{50} & \multirow{3}{*}{ Fitted } & 2 & 0.0534 & 0.9203 & 1 & 0.9873 \\
\hline & & 3 & 0.053 & 0.9493 & 0.862 & 0.8947 \\
\hline & & $2: 3$ & 0.0531 & 1 & 1 & 0.9889 \\
\hline & \multirow{3}{*}{ Regressor } & 2 & 0.0492 & 0.9075 & 1 & 0.9948 \\
\hline & & 3 & 0.0468 & 1 & 0.9859 & 0.9629 \\
\hline & & $2: 3$ & 0.0501 & 1 & 1 & 0.9973 \\
\hline & \multirow{3}{*}{ Princomp } & 2 & 0.0506 & 0.9196 & 1 & 0.9986 \\
\hline & & 3 & 0.0484 & 1 & 0.9884 & 0.9665 \\
\hline & & $2: 3$ & 0.0523 & 1 & 1 & 0.999 \\
\hline \multirow{9}{*}{100} & \multirow{3}{*}{ Fitted } & 2 & 0.0511 & 0.9583 & 1 & 0.9911 \\
\hline & & 3 & 0.0507 & 0.9981 & 0.9524 & 0.9585 \\
\hline & & $2: 3$ & 0.0475 & 1 & 1 & 0.9921 \\
\hline & \multirow{3}{*}{ Regressor } & 2 & 0.0505 & 0.9516 & 1 & 1 \\
\hline & & 3 & 0.0525 & 1 & 0.999 & 0.9784 \\
\hline & & $2: 3$ & 0.0454 & 1 & 1 & 1 \\
\hline & \multirow{3}{*}{ Princomp } & 2 & 0.0513 & 0.9583 & 1 & 1 \\
\hline & & 3 & 0.0509 & 1 & 0.9991 & 0.9805 \\
\hline & & $2: 3$ & 0.0474 & 1 & 1 & 1 \\
\hline \multirow{9}{*}{200} & \multirow{3}{*}{ Fitted } & 2 & 0.0482 & 0.9878 & 1 & 0.9941 \\
\hline & & 3 & 0.05 & 1 & 0.9942 & 0.985 \\
\hline & & $2: 3$ & 0.0488 & 1 & 1 & 0.9947 \\
\hline & \multirow{3}{*}{ Regressor } & 2 & 0.0498 & 0.9855 & 1 & 1 \\
\hline & & 3 & 0.0489 & 1 & 1 & 0.9876 \\
\hline & & $2: 3$ & 0.048 & 1 & 1 & 1 \\
\hline & \multirow{3}{*}{ Princomp } & 2 & 0.0487 & 0.9879 & 1 & 1 \\
\hline & & 3 & 0.0486 & 1 & 1 & 0.9881 \\
\hline & & $2: 3$ & 0.0489 & 1 & 1 & 1 \\
\hline
\end{tabular}
models
Figure 6. Terasvirta's power test for linear and nonlinear

Table 2. Power value of White and Terasvirta test on linear and nonlinear models

\begin{tabular}{llllll}
\hline $\begin{array}{l}\text { Sample } \\
\text { Size }\end{array}$ & $\begin{array}{l}\text { Type of } \\
\text { Test }\end{array}$ & $\begin{array}{l}\text { Model } \\
\mathbf{1}\end{array}$ & $\begin{array}{l}\text { Model } \\
\mathbf{2}\end{array}$ & $\begin{array}{l}\text { Model } \\
\mathbf{3}\end{array}$ & $\begin{array}{l}\text { Model } \\
\mathbf{4}\end{array}$ \\
\hline White & & & & & \\
50 & Chisq & 0.064 & 0.853 & 0.780 & 0.762 \\
& F & 0.054 & 0.846 & 0.752 & 0.737 \\
100 & Chisq & 0.060 & 0.923 & 0.835 & 0.809 \\
& F & 0.056 & 0.920 & 0.832 & 0.799 \\
200 & Chisq & 0.052 & 0.963 & 0.883 & 0.854 \\
& F & 0.052 & 0.964 & 0.889 & 0.851 \\
\hline \multirow{2}{*}{ Terasvirta } & & & & & \\
\multirow{2}{*}{50} & Chisq & 0.104 & 1 & 1 & 1 \\
& F & 0.060 & 1 & 1 & 1 \\
100 & Chisq & 0.069 & 1 & 1 & 1 \\
& F & 0.051 & 1 & 1 & 1 \\
& Chisq & 0.056 & 1 & 1 & 1 \\
& F & 0.047 & 1 & 1 & 1 \\
\hline
\end{tabular}
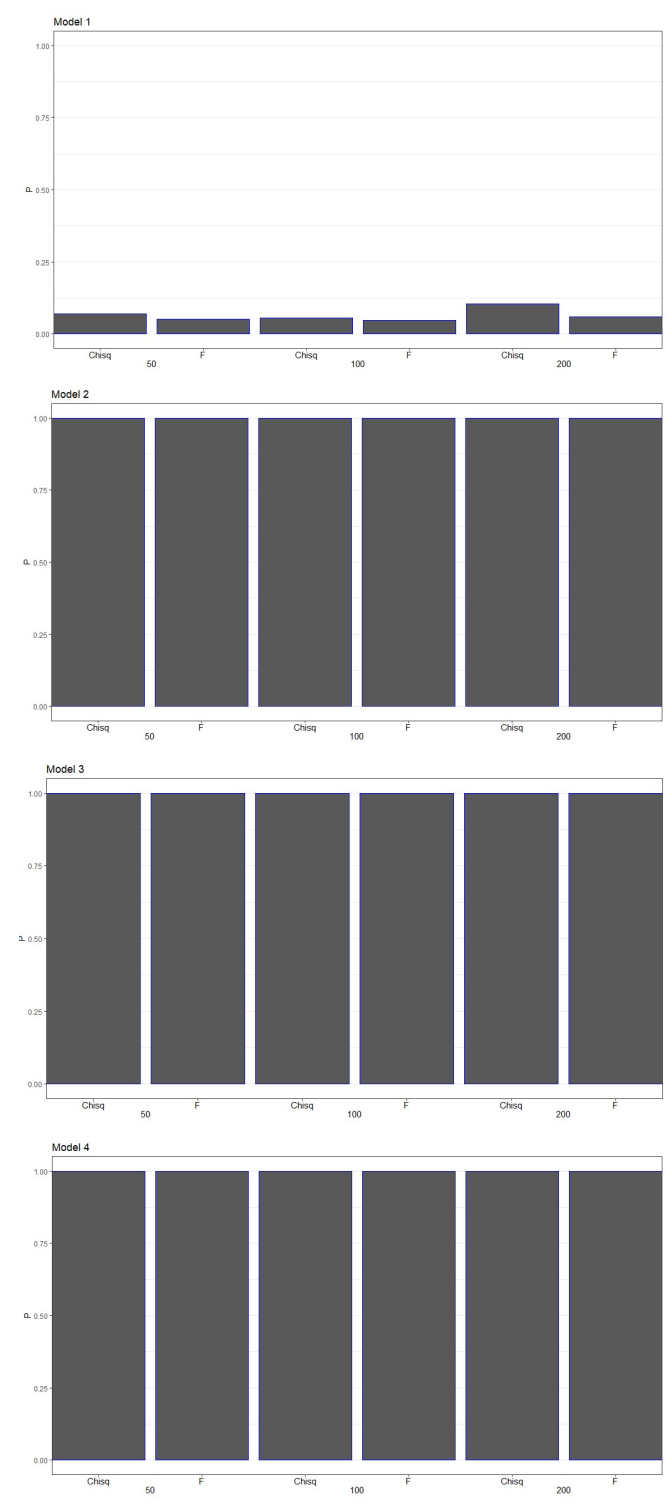

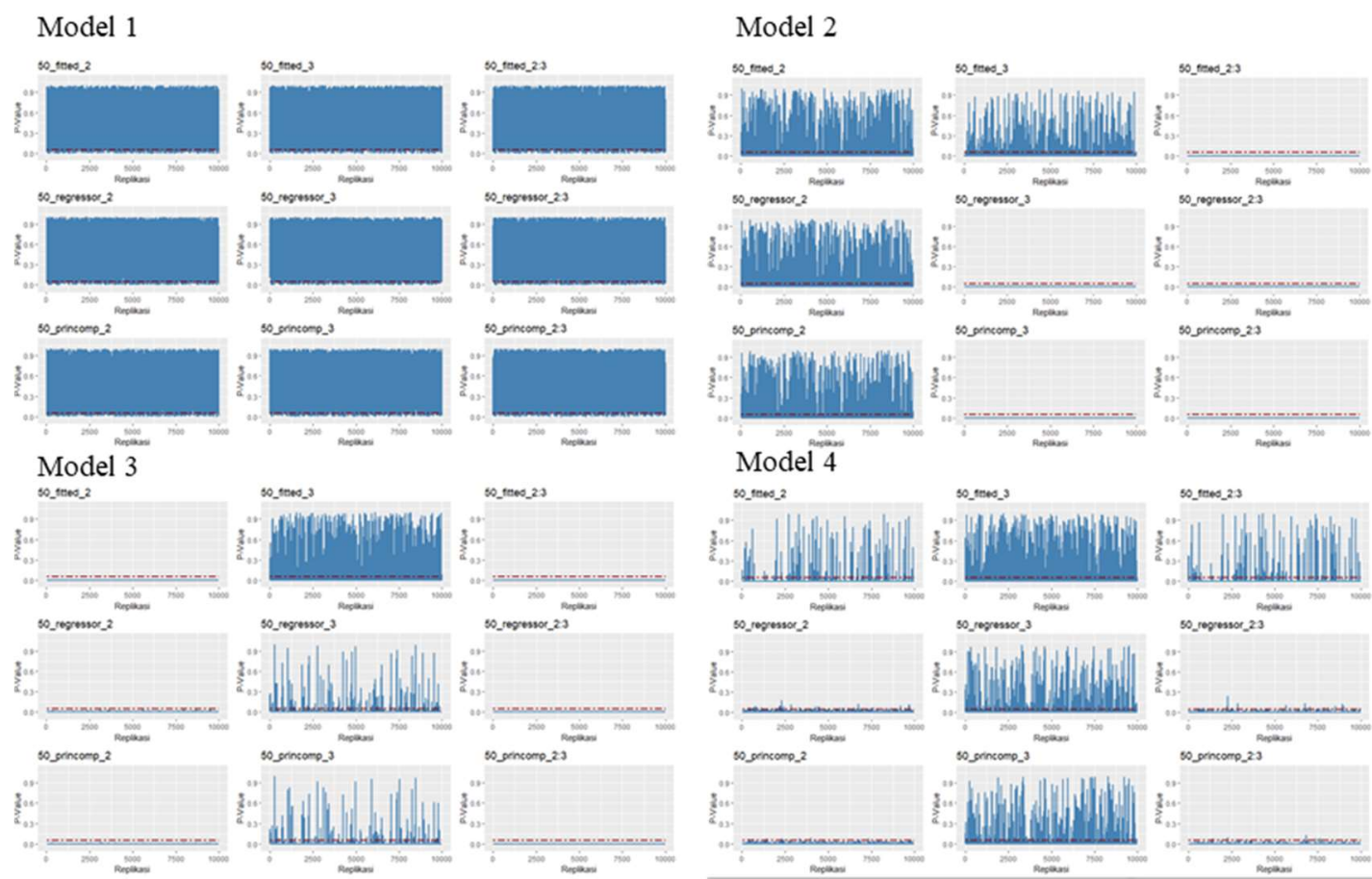

Figure 7. Time series plot for each linear and nonlinear model with sample size 50 from the $10000 \mathrm{p}$-value replication uses the Ramsey test
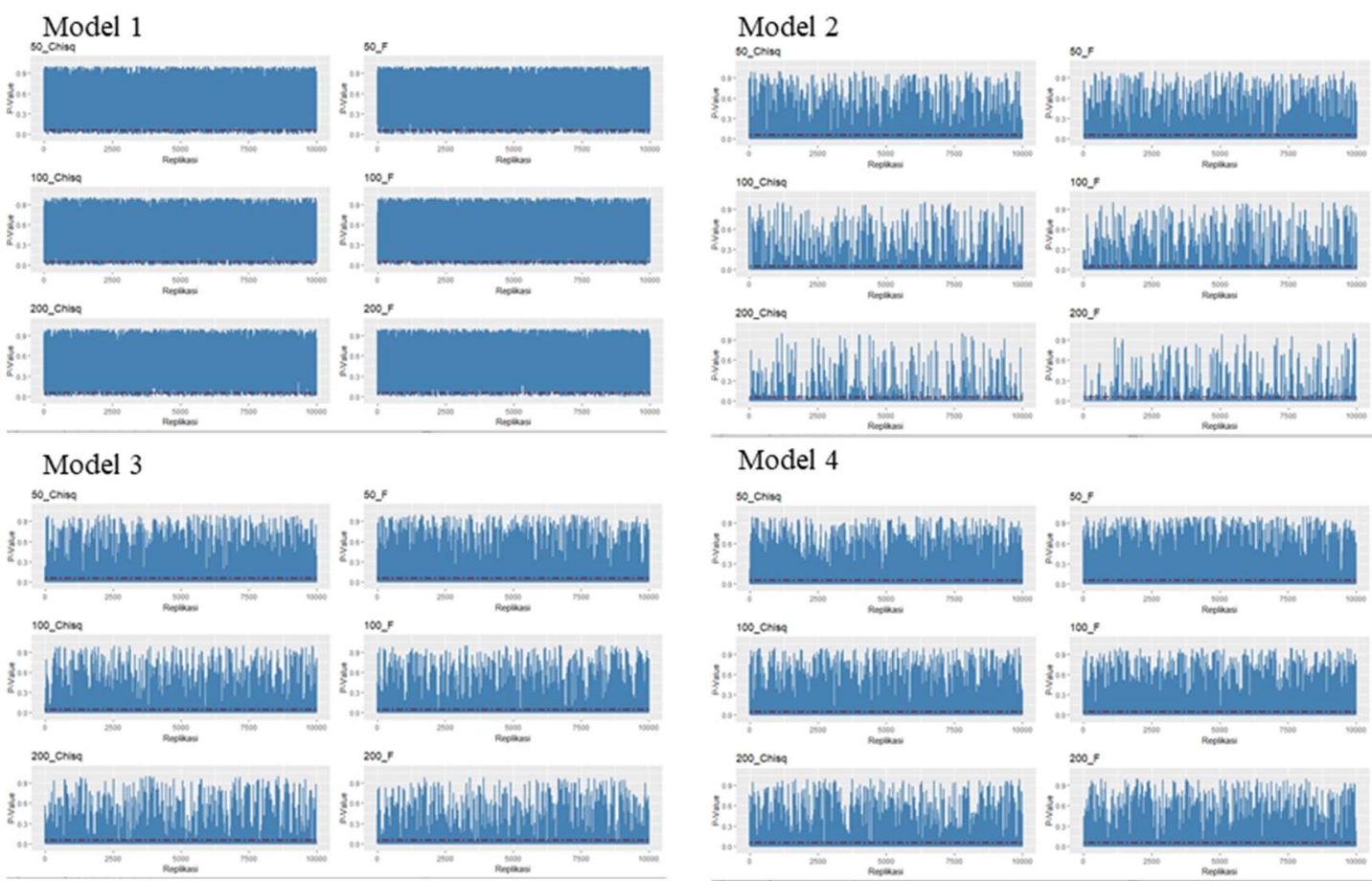

Figure 8. Time series plot for each linear and nonlinear model and each scenario from 10000 p-value replication uses White test 

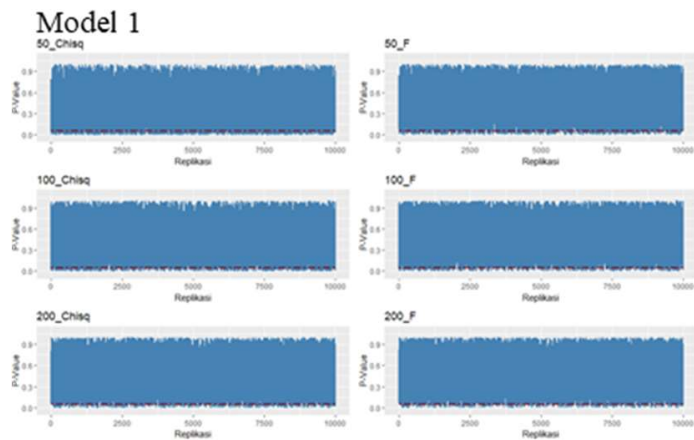

Model 3
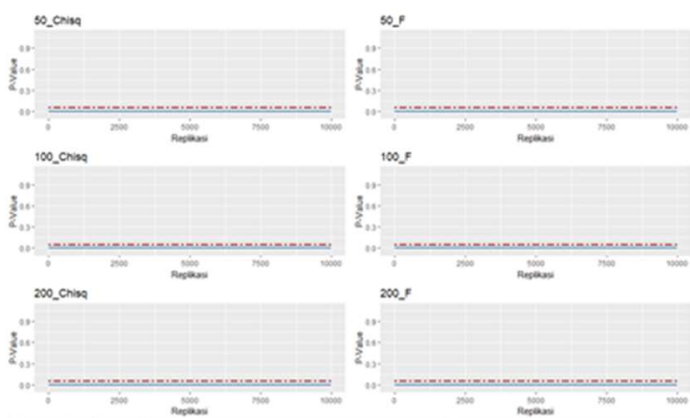

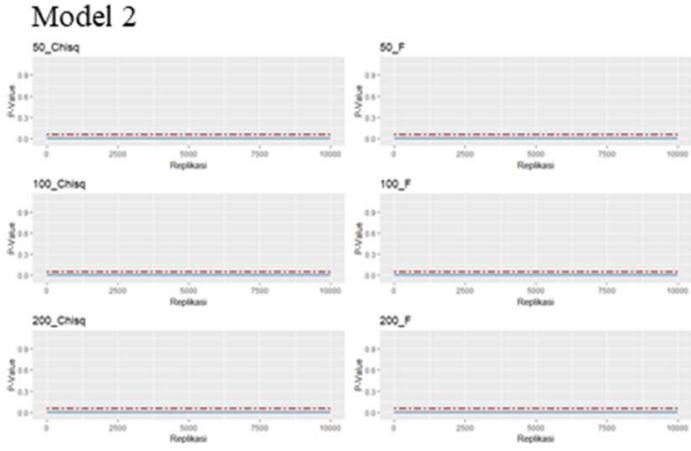

Model 4
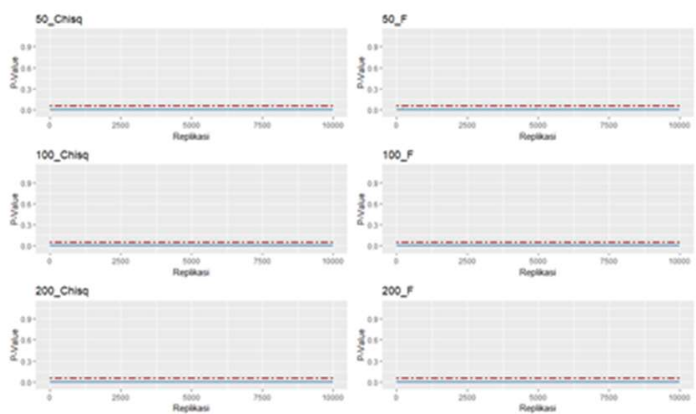

Figure 9. Time series plot for each linear and nonlinear model and each scenario from $10000 \mathrm{p}$-value replication uses Terasvirta test
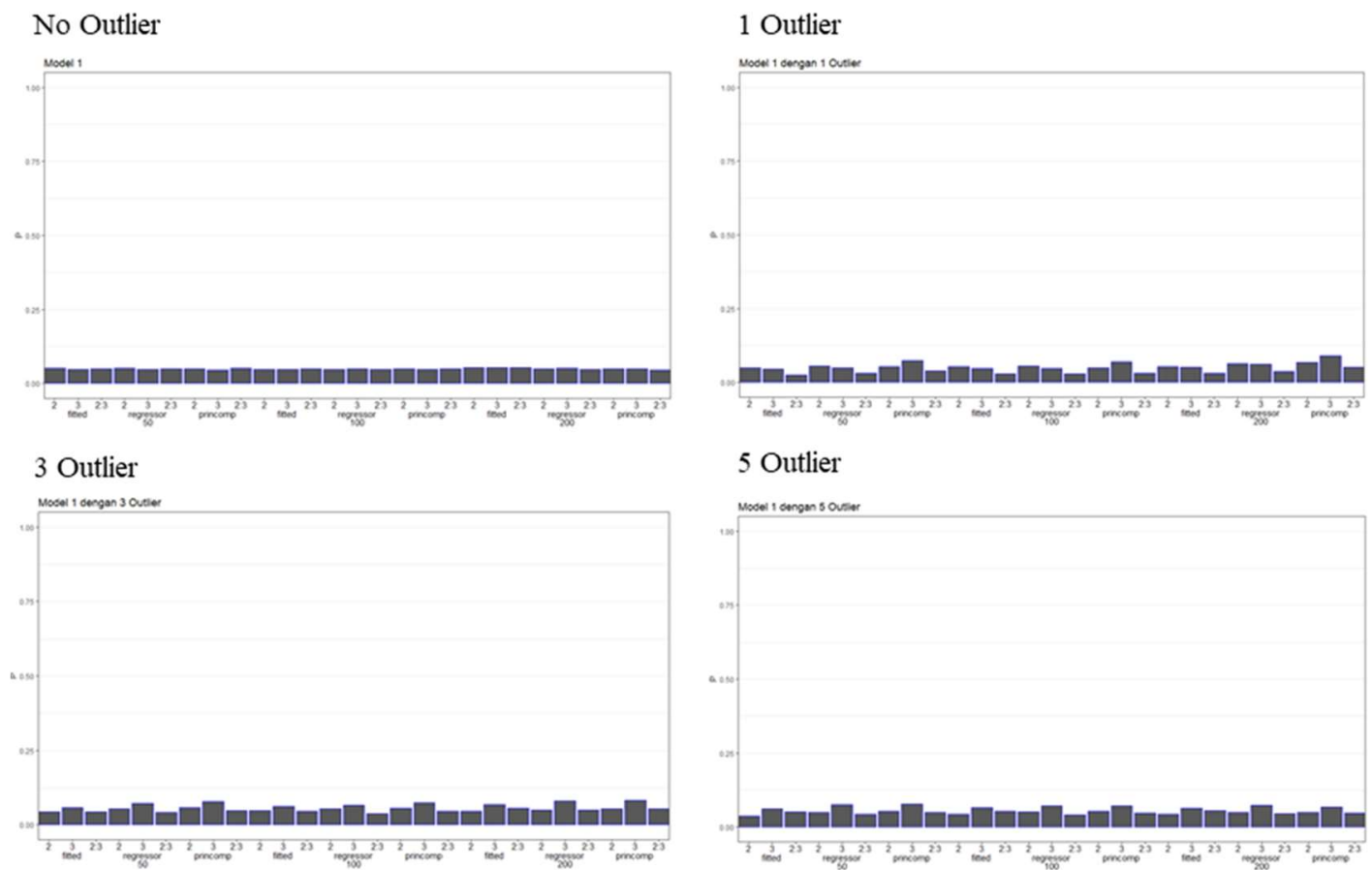

Figure 10. Ramsey's power test for linear model with outlier 

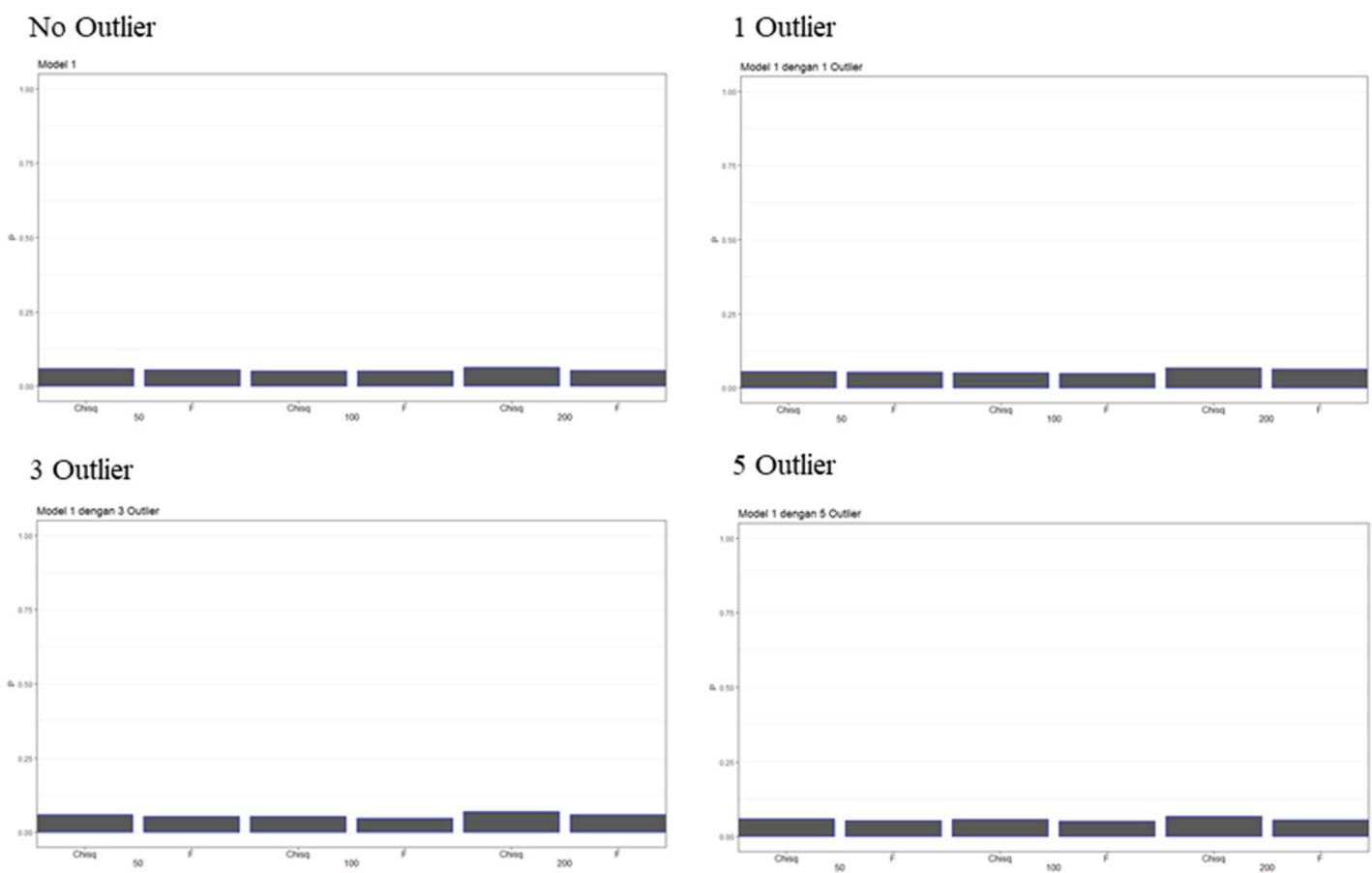

$$
5 \text { Outlier }
$$

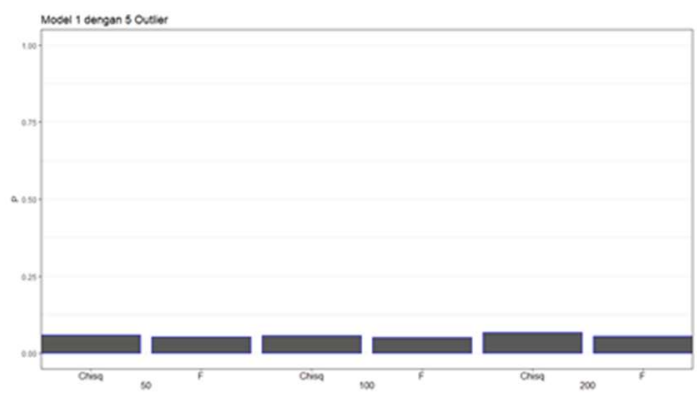

Figure 11. White's power test for linear model with outlier

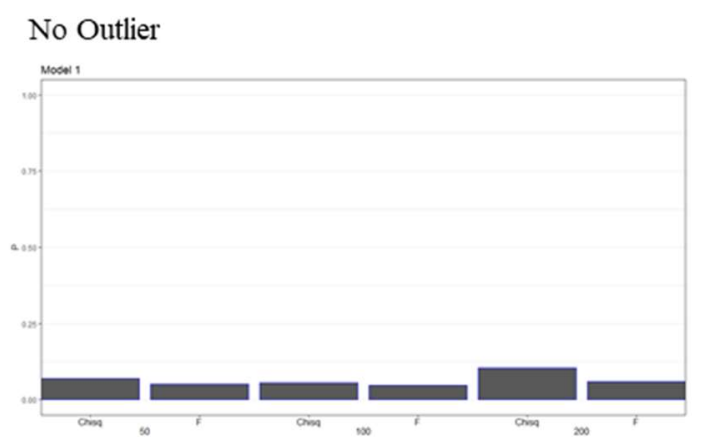

$$
1 \text { Outlier }
$$

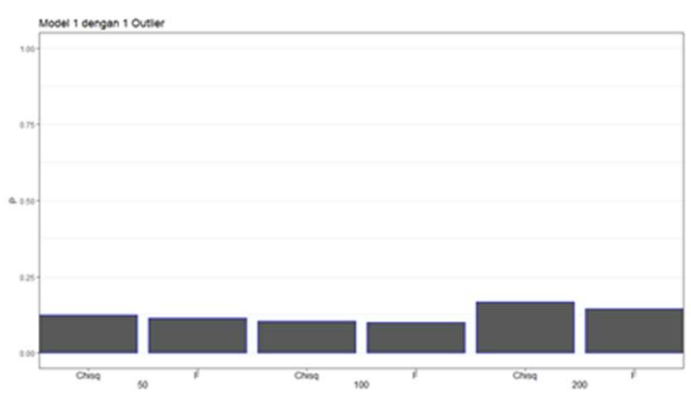

3 Outlier

5 Outlier
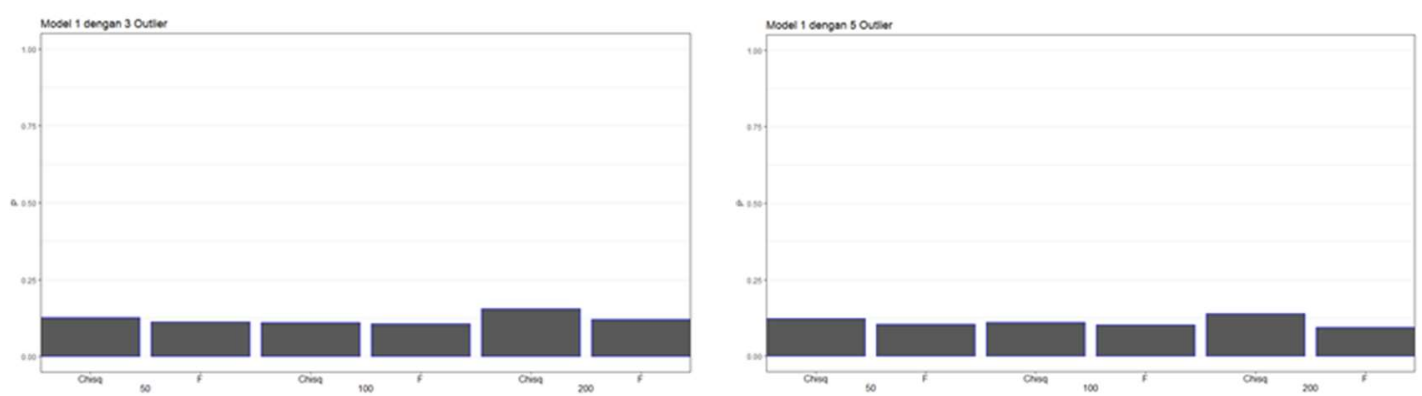

Figure 12. Terasvirta's power test for linear model with outlier 


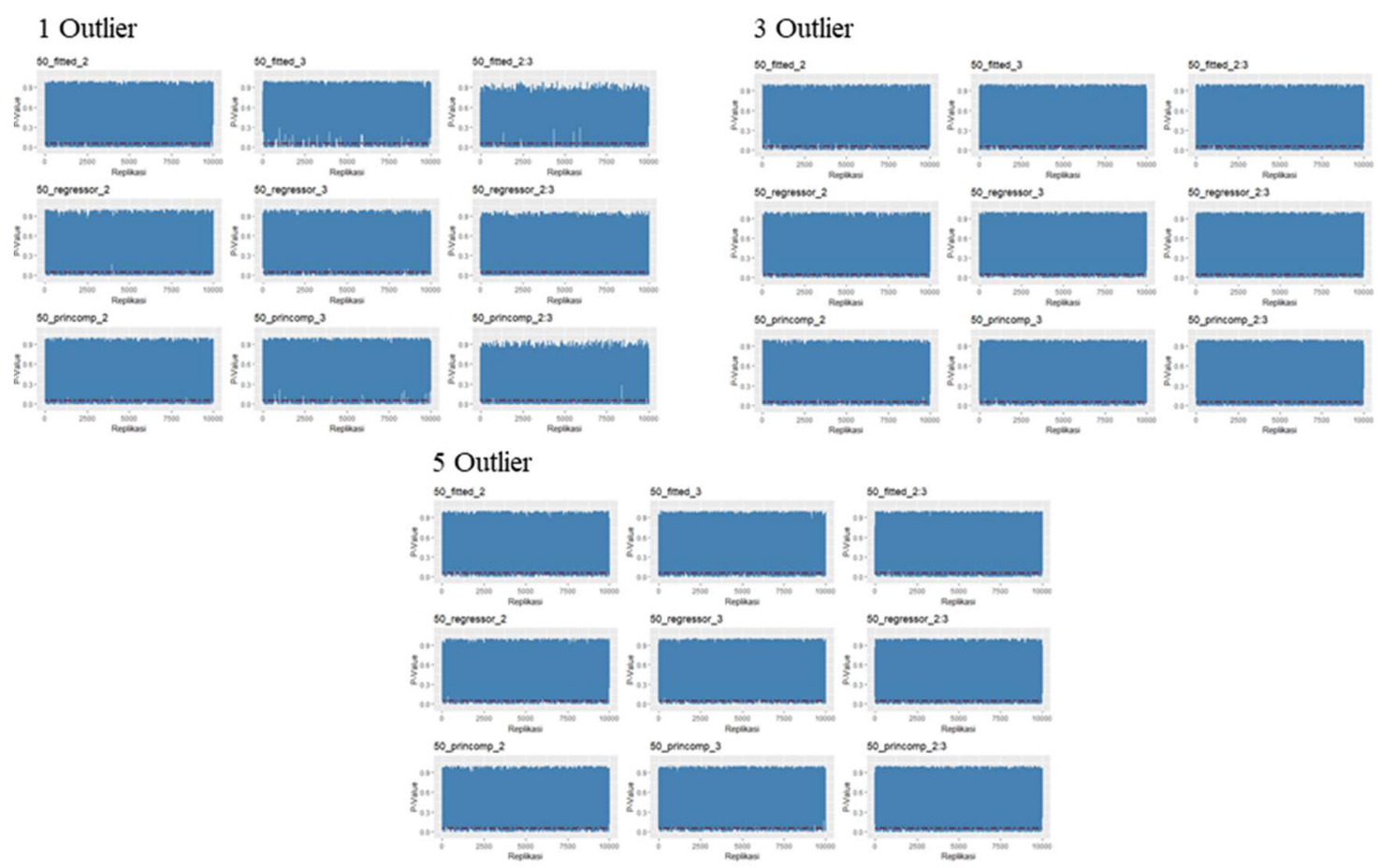

Figure 13. Time series plot for each linear model with outlier by sample size 50 from the 10000 p-value replication uses the Ramsey test
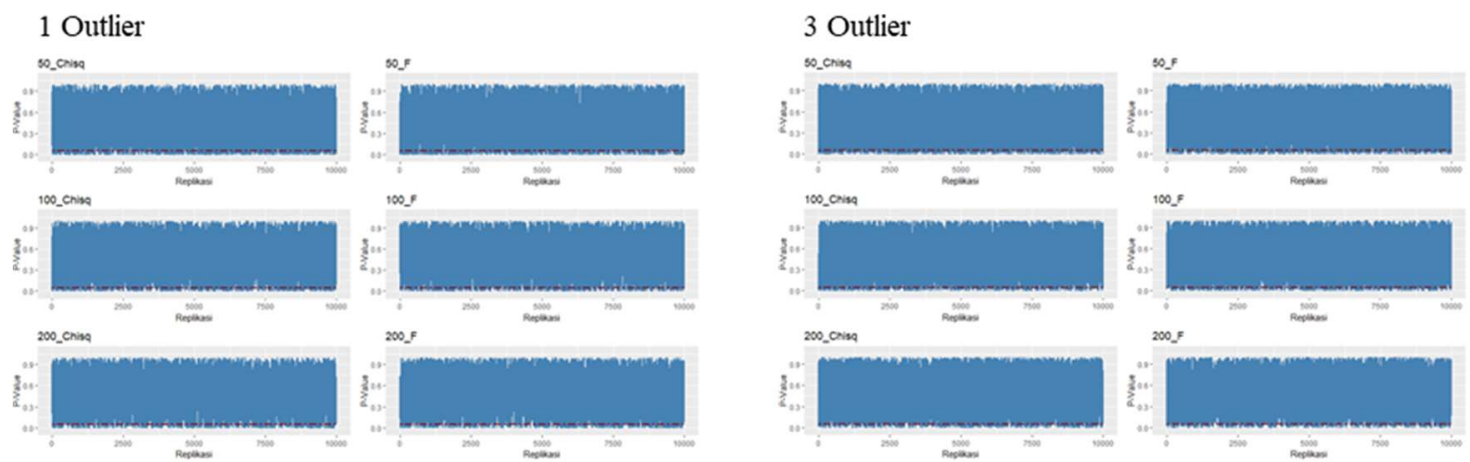

$$
2000 \text { Cons }
$$

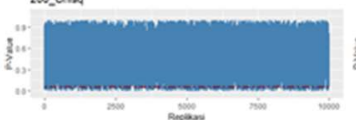

$200, F$

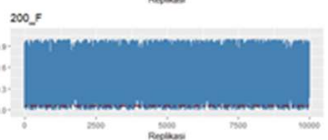

\section{Outlier}
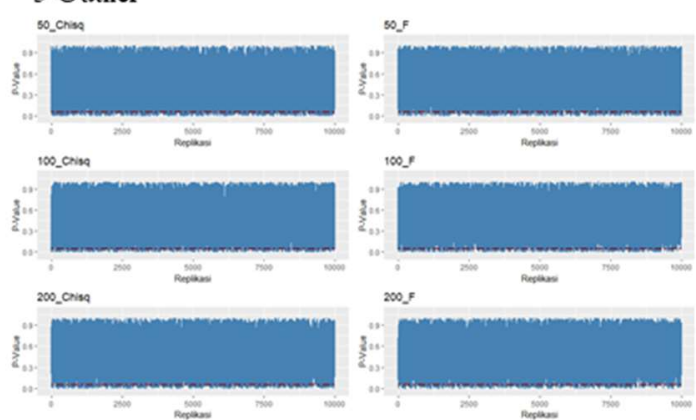

$200 \%$

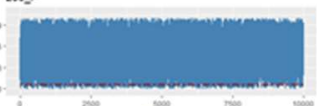

Figure 14. Time series plot for each linear model with outlier and each scenario from 10000 p-value replication uses White test 

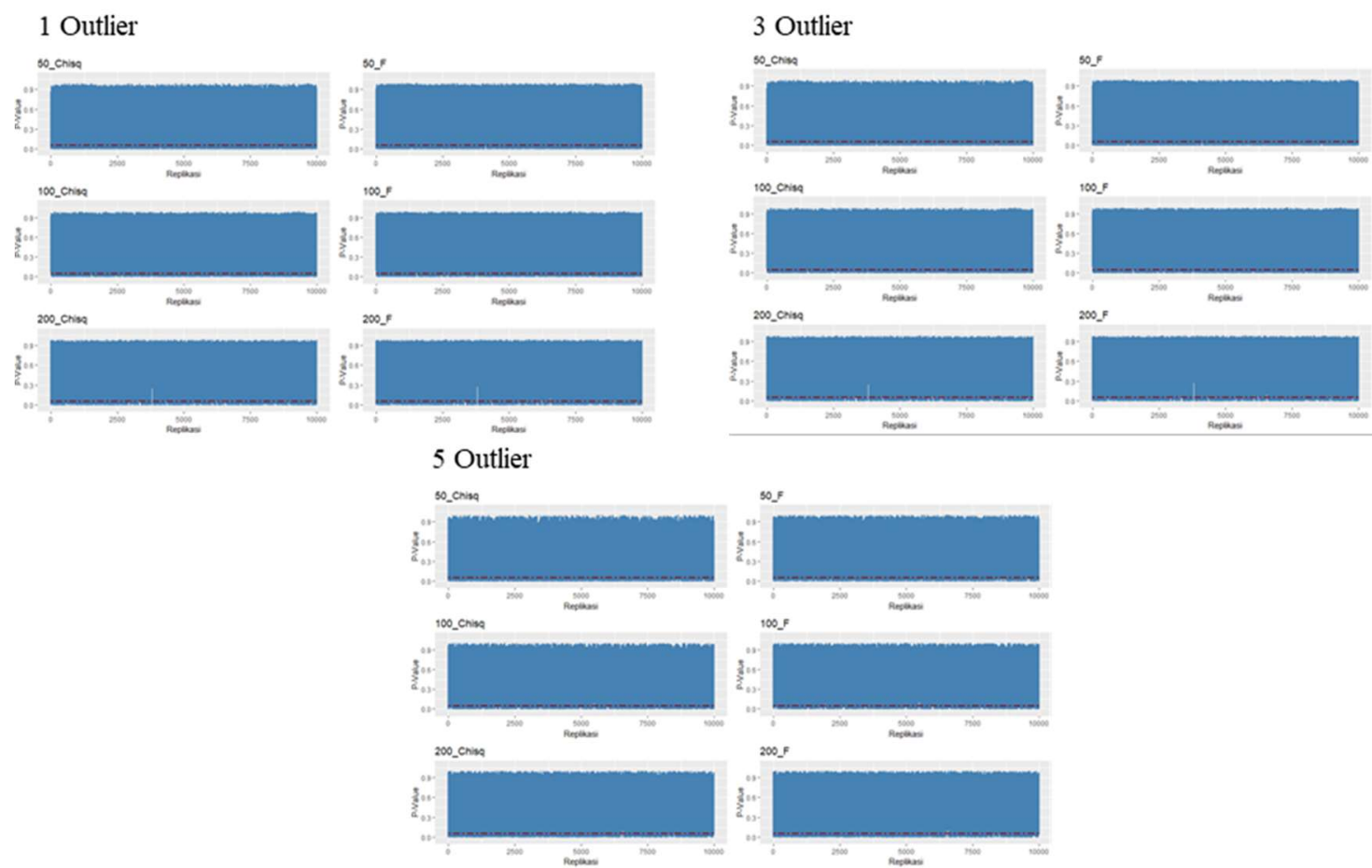

Figure 15. Time series plot for each linear model with outlier and each scenario from 10000 p-value replication uses Terasvirta test

\section{Power Comparison Result for Each Nonlinearity Test in Linear Model with Outlier}

From Figure 10 it can be seen that in general the linear model added 1 outlier, 3 outlier and 5 outlier, based on the Ramsey test the model remains linear. But it should be noted that the presence of this outlier resulted the power of Ramsey test is not around the significance level 0.05. The power value is around 0.1, although there are a number of scenarios that have decreased power.

Based on Figure 11 in general the existence of 1, 3 and 5 outliers does not affect the linearity of the model based on White test. The power of this White test for all scenarios approaches the significance level of 0.05 . In general based on Figure 12, it can be seen that Terasvirta test is more sensitive to the presence of outliers in the linear model when compared to Ramsey test and White test. This Terasvirta power test is not around the significance level 0.05 but it is around 0.1. From Figure 12, it can be seen if the Chisq test statistics used in the Terasvirta test will be more sensitive to outliers. It can also be seen in Table 3 and Table 4, where the power value of Terasvirta test is greater than other tests in detecting linear models with the addition of outliers.

Based on Figure 11 in general the existence of 1, 3 and 5 outliers does not affect the linearity of the model based on White test. The power of this White test for all scenarios approaches the significance level of 0.05 . In general based on Figure 12, it can be seen that Terasvirta test is more sensitive to the presence of outliers in the linear model when compared to Ramsey test and White test. This Terasvirta power test is not around the significance level 0.05 but it is around 0.1 . From Figure 12, it can be seen if the Chisq test statistics used in the Terasvirta test will be more sensitive to outliers. It can also be seen in Table 3 and Table 4, where the power value of Terasvirta test is greater than other tests in detecting linear models with the addition of outliers.

To see the p-value consistency of each test at 10000 replications, we can use the time series plot. From Figure 13, Figure 14 and Figure 15, it can be seen that with Ramsey test, White test and Terasvirta test with various scenarios in the linear model with outliers, the p-value is consistently above 0.05 . This means that from the tests conducted in 10000 replications the results are consistent that the model is a linear model. In general, having a small number of outliers in a linear model does not change the linearity of the data.

In general, the results of research conducted indicate that Terasvirta test has greater power in the detection of nonlinearity than the other test. In a study conducted by Ahn et al. [8] showed that Ramsey test in general has better power in the detection of nonlinearity and from research conducted by Lee et al. [9] in general White test has better power. In this study the two nonlinearity tests that had the best power were Ramsey test and White test compared to Terasvirta test. The result showed that Terasvirta test has better power in the detection of nonlinearity. 
Table 3. Power value of Ramsey test on linear model with

\begin{tabular}{|c|c|c|c|c|c|}
\hline $\begin{array}{c}\text { Sample } \\
\text { Size }\end{array}$ & $\begin{array}{c}\text { Type of } \\
\text { Predictor }\end{array}$ & $\begin{array}{c}\text { Type of } \\
\text { Power }\end{array}$ & $\begin{array}{c}1 \\
\text { Outlier } \\
\end{array}$ & $\begin{array}{c}3 \\
\text { Outlier } \\
\end{array}$ & $\begin{array}{c}5 \\
\text { Outlier } \\
\end{array}$ \\
\hline \multirow{9}{*}{50} & \multirow{3}{*}{ Fitted } & 2 & 0.0544 & 0.0458 & 0.0447 \\
\hline & & 3 & 0.0311 & 0.0556 & 0.0555 \\
\hline & & $2: 3$ & 0.0515 & 0.0686 & 0.0644 \\
\hline & \multirow{3}{*}{ Regressor } & 2 & 0.0677 & 0.0541 & 0.0506 \\
\hline & & 3 & 0.0512 & 0.0549 & 0.0474 \\
\hline & & $2: 3$ & 0.0906 & 0.0815 & 0.0676 \\
\hline & \multirow{3}{*}{ Princomp } & 2 & 0.0641 & 0.0507 & 0.0495 \\
\hline & & 3 & 0.0384 & 0.0497 & 0.0449 \\
\hline & & $2: 3$ & 0.0621 & 0.0796 & 0.0746 \\
\hline \multirow{9}{*}{100} & \multirow{3}{*}{ Fitted } & 2 & 0.0503 & 0.0439 & 0.0381 \\
\hline & & 3 & 0.0262 & 0.0437 & 0.0514 \\
\hline & & $2: 3$ & 0.0455 & 0.059 & 0.0617 \\
\hline & \multirow{3}{*}{ Regressor } & 2 & 0.0537 & 0.0584 & 0.053 \\
\hline & & 3 & 0.0403 & 0.0488 & 0.0493 \\
\hline & & $2: 3$ & 0.0734 & 0.0781 & 0.0785 \\
\hline & \multirow{3}{*}{ Princomp } & 2 & 0.055 & 0.0537 & 0.049 \\
\hline & & 3 & 0.0318 & 0.0412 & 0.0436 \\
\hline & & $2: 3$ & 0.0495 & 0.0716 & 0.0754 \\
\hline \multirow{9}{*}{200} & \multirow{3}{*}{ Fitted } & 2 & 0.0537 & 0.0475 & 0.0446 \\
\hline & & 3 & 0.0292 & 0.0461 & 0.0535 \\
\hline & & $2: 3$ & 0.0469 & 0.0618 & 0.0658 \\
\hline & \multirow{3}{*}{ Regressor } & 2 & 0.0506 & 0.0566 & 0.0534 \\
\hline & & 3 & 0.0319 & 0.0466 & 0.0475 \\
\hline & & $2: 3$ & 0.0706 & 0.0738 & 0.0724 \\
\hline & \multirow{3}{*}{ Princomp } & 2 & 0.0562 & 0.0543 & 0.051 \\
\hline & & 3 & 0.0296 & 0.0386 & 0.0425 \\
\hline & & $2: 3$ & 0.0486 & 0.067 & 0.0723 \\
\hline
\end{tabular}

Table 4. Power value of White and Terasvirta test on linear model with outlier

\begin{tabular}{ccccc}
\hline Sample Size & Type of Test & 1 Outlier & 3 Outlier & 5 Outlier \\
\hline \multirow{2}{*}{50} & Chisq & White & & \\
& F & 0.0674 & 0.0696 & 0.0687 \\
\multirow{2}{*}{100} & Chisq & 0.0569 & 0.0602 & 0.057 \\
& F & 0.0545 & 0.0545 & 0.0532 \\
\multirow{2}{*}{200} & Chisq & 0.051 & 0.0535 & 0.059 \\
& F & 0.0498 & 0.0488 & 0.0512 \\
\hline \multirow{4}{*}{50} & & Terasvirta & & \\
& Chisq & 0.1675 & 0.156 & 0.1401 \\
100 & F & 0.1456 & 0.1204 & 0.0953 \\
& Chisq & 0.1243 & 0.1263 & 0.1227 \\
\multirow{2}{*}{200} & F & 0.1145 & 0.1126 & 0.1052 \\
& Chisq & 0.1047 & 0.112 & 0.1102 \\
& F & 0.1011 & 0.1061 & 0.103 \\
\hline
\end{tabular}

\section{CONCLUSIONS}

Based on the results of simulation studies conducted using various scenarios and comparisons of Ramsey test, White test and Terasvirta test. The results obtained that Terasvirta test is a better test in detecting nonlinearity compared to Ramsey test and White test. It can be seen from the very high Terasvirta test power (close to 1) when detecting nonlinearity in nonlinear models. It can also be concluded that Terasvirta test is more sensitive to outliers (in detecting nonlinearity models). It can be seen from Terasvirta power test that higher compared to Ramsey test and White test. The results of this study also showed that White test tended to have lower power compared to Ramsey test and Terasvirta test. It happen because the weight selection in White test uses random sampling. So that in future studies another way to determine weight can be done, not just using random sampling. Besides that, in further research, other nonlinearity tests can be used such as RBF test [11] to be compared.

\section{REFERENCES}

[1] J. B. Ramsey, "Tests for Specification Errors in Classical Linear Least Squares Regression," Journal of the Royal Statistical Society, Series B, Vol. 31, pp. 350-371, 1969.

[2] H. White, "An Additional Hidden Unit Test for Neglected Nonlinearity in Multilayer Feedforward Networks," in Proceedings of The International Joint Conference on Neural Networks, San Diego, 1989.

[3] T. Terasvirta, C. F. Lin and C. W. J. Granger, "Power of the Neural Networks Linearity Test," Journal of Time Series Analysis Vol. 14, pp. 159-171, 1993.

[4] D. N. Gujarati, Basic Econometrics, New York: The McGraw-Hill Companies, 2004.

[5] M. Mahdiloo, M. Toloo, T. T. Duong, R. F. Saen and P. Tatham, "Integrated Data Envelopment Analysis: Linear vs. Nonlinear Model," European Journal of Operational Research Vol. 268, pp. 255-267, 2018.

[6] R. Wang, B. Morley and M. P. Stamatogiannis, "Forecasting the Exchange Rate Using Nonlinear Taylor Rule Based Models," International Journal of Forecasting Vol. 35, pp. 429-442, 2019.

[7] M. Lacheheb and A. Sirag, "Oil price and Inflation in Algeria: A Nonlinear ARDL Approach," The Quarterly Review of Economics and Finance Vol. 73, pp. 217-222, 2019.

[8] E. S. Ahn and J. M. Lee, "The Performance Of Nonlinearity Tests On Asymmetric Nonlinear Time Series," The Journal of Economic Asymmetries Vol. 9 (2), pp. 11-44, 2012.

[9] A. Borah and B. Nath, "Incremental Rare Pattern Based Approach for Identifying Outliers in Medical Data," Applied Soft Computing Vol. 85, p. 105824, 2019.

[10] T. H. Lee, H. White and C. J. W. Granger, "Testing for Neglected Nonlinearity in Time Series Models: A Comparison of Neural Network Methods and Alternative Tests," Journal of Econometrics Vol. 56, pp. 269-290, 1993. 
[11] A. P. Blake and G. Kapetanios, "A Radial Basis Function Artificial Neural Networks Test for Neglected Nonlinearity," Econometrics Journal Vol. 6, pp. 356-372, 2003. 